\title{
ACEITAÇÃO DA MUDANÇA E DESEMPENHO DOS \\ ENFERMEIROS: A IMPORTÂNCIA DO CUMPRIMENTO DAS OBRIGAÇÕES POR PARTE DO HOSPITAL ${ }^{1}$
}

\author{
Maria José Chambel ${ }^{2}$ \\ Luís Sousa
}

Resumo: Neste trabalho, analisámos a aceitação da mudança no sector da saúde por parte dos enfermeiros. Este estudo procurou integrar a perspectiva que considera a interpretação das razões da mudança (Rousseau \& Tijoriwala, 1999; Shapiro, Buttner \& Burry, 1994) e aquela que considera a ruptura no cumprimento das obrigações da organização (Robinson, 1996) como cruciais para explicar a aceitação da mudança por parte dos empregados. Salientámos a importância dessa aceitação, analisando a sua influência no desempenho e Comportamentos de Cidadania Organizacional (CCO) dos empregados.

Com uma amostra de 467 enfermeiros de diferentes hospitais da região de Lisboa, verificámos que a aceitação desta mudança hospitalar, com repercussões nas práticas de gestão dos recursos humanos, era não só influenciada pelas razões comunicadas pela hierarquia, mas também pela percepção do cumprimento das obrigações por parte do hospital durante este processo. No entanto, não se verificou o efeito pressuposto de moderação do cumprimento das obrigações sobre a relação entre o tipo de razão e sua aceitação. Além disso, verificou-se que a aceitação desta mudança por parte dos enfermeiros era uma variável com influência nos seus comportamentos de cidadania organizacional (avaliados pela chefia directa).

Palavras-chave: Mudança Organizacional, Aceitação da Mudança, Contrato Psicologico, Desempenho, Comportamentos de Cidadania Organizacional e Enfermeiros.

\footnotetext{
${ }^{1}$ A correspondência relativa a este artigo deverá ser endereçada a Maria José Chambel, Faculdade de Psicologia e Ciências da Educação, Universidade de Lisboa, Alameda da Universidade, 1649-013 Lisboa, Portugal, e-mail: mjchambel@fpce.ul.pt

2 Faculdade de Psicologia e de Ciências da Educação, Universidade de Lisboa.

${ }^{3}$ Instituto de Superior de Ciências do Trabalho e da Empresa. Hospital de Curry Cabral, Lisboa.

${ }^{4}$ Alterado pelos Decreto-Lei n. ${ }^{\circ} 412 / 98$, de 30 de Dezembro, e Decreto-Lei n. ${ }^{\circ} 411 / 99$, de 15 de Outubro.
} 
Change acceptance and nurses' performance: The importance of obligations fulfillment by hospital (Abstract): With this work, one has explored the reasons acceptance of the changes that had occurred in the healthcare sector, as far as the influence of this acceptance in nurses' performance and Organizational Citizenship Behavior (OCB) is concerned. This study, intended to integrate the perspective that considers the interpretation of the reasons of change (Rousseau \& Tijoriwala, 1999; Shapiro, Buttner \& Burry, 1994) and the perspective that considers the breach in the organization's obligation fulfilment (Robinson, 1996) as crucial to explain the acceptance of the change by the employees.

With a sample of 467 nurses from different hospitals in the Lisbon area the data analysis, it was verified that the acceptance of the Organizational changing with practical repercussions in the human resource management, was not only influenced by the reasons communicate from leaders, but also by the perceived fulfilment of the hospital obligations. However, one did not verify the interaction effects of obligations' fulfilment between the sort of reason and its acceptance. In addition, it was verified that the acceptance of this change by nurses was a variable with influence in the Organizational Citizenship Behavior.

Key-words: Organizational Change, Change Acceptance, Psychological Contract, Performance, Organizational Citizenship Behavior and Nurses.

\section{Introdução}

No dia-a-dia, ocorrem, com alguma frequência, mudanças nas organizações, visando responder às ameaças, desafios e oportunidades da sua envolvente. As organizações empreendem essas mudanças com o objectivo de melhorar o seu desempenho e a sua perenidade. Neste contexto de constante instabilidade, a gestão da mudança tem sido uma das preocupações fundamentais, tanto de académicos das ciências sociais e humanas, como de gestores. Concretamente, as respostas dos colaboradores às mudanças organizacionais têm ocupado um lugar de destaque, porque se sabe que as reacções das pessoas perante este processo podem pôr em causa a sua eficácia.

No sentido de aumentar a confiança dos colaboradores na implementação de uma mudança, Huy (1999) sustenta que, quando uma mudança é proposta, tem de desencadear receptividade cognitiva e emocional por parte dos participantes organizacionais, o que implica: tornar a mudança legítima e aceite; desenvolver a mobilização (que consiste em fazer com que os diferentes participantes e grupos se empenhem na realização de acções comuns e adiram aos objectivos da mudança); avaliar os resultados das acções (o que possibilita uma aprendizagem a partir dos resultados e aumenta a receptividade das acções alternativas, num processo contínuo de aprendizagem). 
Alguns estudos mostraram que a maneira como as organizações constroem a mudança influencia as respostas dos empregados (Fairhurst \& Sarr, 1996) e que o modo como os empregados interpretam as razões da mudança influencia as suas reacções para com esta (Shapiro, Buttner \& Barry, 1994).

\section{O Motivo social}

O motivo social tem sido definido como as justificações utilizadas pela gestão para explicar as acções empreendidas na empresa, nomeadamente as acções de mudança, as quais, em função de adequabilidade ou credibilidade da razão e a sinceridade do motivo atribuído, influenciam as reacções dos empregados (Bies \& Moag, 1986; Bies \& Shapiro, 1993).

Por exemplo, Bies e Shapiro (1987) estudaram como é que os colaboradores reagiam à presença ou ausência de razões da mudança implementadas pelos gestores e concluíram que a comunicação dos motivos das decisões diminuía a culpa atribuída aos gestores e, consequentemente, aumentava a aceitação da mudança. De facto, os estudos de Folger, Rosenfield e Robinson (1983), Folger e Martin (1986) tinham mostrado que as justificações adequadas das razões da mudança por parte dos gestores diminuíam a presença de sentimentos de descontentamento dos empregados para com as decisões tomadas. No entanto, verificou-se que não era apenas necessário comunicar os motivos da mudança, mas apresentar motivos legítimos. Os estudos de Shapiro e Bies (1992) e Sitkin e Roth (1993) vieram mostrar que, se os empregados consideravam que estavam a ser enganados pelas explicações dos gestores, apresentavam sentimentos de traição e desconfiança, os quais os levavam a elevados níveis de conflito e retaliação (Sitkin \& Bies, 1993).

Várias variáveis podem influenciar essa legitimidade ou aceitação dos motivos da mudança. Bies (1987) argumentou que a confiança na gestão influenciava positivamente a credibilidade e a legitimidade da razão da mudança, fazendo com que os empregados que confiassem na gestão aceitassem mais os motivos da gestão como justificação da mudança. Shapiro (1991) descobriu que o próprio conteúdo dos motivos apresentados influenciava a legitimidade percebida desses mesmos motivos. Por exemplo, numa situação de fraude, os motivos que focavam apenas uma causa de fraude eram percebidos como mais adequados do que as explicações que apresentavam mais que uma intenção de acção fraudulenta. Por outro lado, quando os indivíduos eram enganados pelos seus parceiros de negócio, a honestidade percebida dos motivos dados mediava a efectividade das explicações (Sitkin \& Bies, 1993).

Bies e Shapiro $(1987,1988)$ e Greenberg (1988) sugeriram que as explicações das razões da mudança podiam influenciar não só os sentimentos de aceitação da mudança, mas também influenciar a percepção de justi- 
ça ou injustiça do processo (Sitkin \& Bies, 1993). Assim, as explicações que davam ênfase às crenças e valores partilhados podiam influenciar positivamente as interpretações sobre os motivos da mudança, levando a sentimentos mais positivos, aumentando a cooperação na implementação das decisões e a adesão a políticas institucionais, porque os trabalhadores compreendiam melhor os interesses organizacionais partilhados.

\section{A Razão Motivada}

Ainda que os gestores possam dar motivos sociais para as suas acções, há uma série de outros factores que contribuem para o processamento de informação dos empregados sobre a mudança (Rousseau \& Tijoriwala, 1999). Concretamente, a teoria da razão motivada procura explicar como é que uma causa específica é adoptada para explicar determinado acontecimento (Rousseau \& Tijoriwala, 1999). Nesta perspectiva, os empregados não são receptores passivos das mensagens da mudança, mas processadores de informação activos que se inserem na selecção causal (Einhorn \& Hogarth, 1986; McGill, 1995). Os factos e perspectivas individuais são uma amálgama de experiências passadas, de informação avaliada, e processos cognitivos que podem levar os empregados da mesma organização a gerarem diferentes explicações para o mesmo acontecimento (McGill, 1995). É na relação dos empregados com a organização que se formam as suas interpretações sobre as acções, essencialmente porque esta relação é um produto da história de vida dos empregados com a organização (Rousseau, 1995). A qualidade das relações de trabalho durante uma mudança planeada apresemta um papel importante na promoção da aceitabilidade e no envolvimento do colaborador (Pfeffer, 1994; Rousseau, 1996).

\section{O Contrato Psicológico}

Numa relação laboral, como em todas as situações de "troca social", entram em acção um conjunto de percepções, expectativas e crenças, realistas ou não, sobre o que o empregador e o empregado darão e receberão como resultado da sua relação, além das obrigações e compensações acordadas explicitamente. A existência desta componente implícita suporta os termos gerais do contrato psicológico, que é reconhecido facilmente pelas partes implicadas numa relação laboral.

Rousseau (1989) definiu contrato psicológico como o conjunto de "Crenças do indivíduo sobre os termos e condições de um acordo de troca recíproco entre a pessoa e a outra parte. Um contrato psicológico surge quando uma parte crê que se fez uma promessa de compensações futuras, se realizou uma retribuição e, em consequência, criou-se a obrigação de proporcionar benefícios futuros" (p. 122). 
Cada contrato psicológico é individual e único e, em teoria, pode aparecer num número ilimitado de formatos, uma vez que os trabalhadores e as organizações têm modos específicos de se expressarem e de interpretarem os termos do contrato. No entanto, esses contratos foram categorizados por Rousseau (1995), que distinguiu:

- Os contratos transaccionais - caracterizam-se por uma duração limitada, sendo que os termos relativos aos requisitos ou exigências do desempenho estão bem especificados;

- Os contratos transicionais - referem-se àqueles que compreendem comdições "sem garantias" sobre a interrupção dos contratos, exprimem ausência de compromisso que permita a possibilidade de futuras relações de trabalho, apresentando poucas ou nenhumas exigências de desempenho ou incentivos explícitos;

- Os contratos relacionais - caracterizam-se pelo seu carácter aberto e pelas suas garantias de continuidade na relação de trabalho, contudo, os requisitos de desempenho são incompletos ou ambíguos;

- Os contratos balanceados - apresentam também um carácter aberto, orientados para a continuidade da relação laboral, com requisitos de desempenho bem especificados, mas que podem alterar-se ao longo do tempo.

Este contrato emerge da noção de reciprocidade na troca que se desenvolve entre empregados e empregador, procurando as partes envolvidas nesta troca manter o equilíbrio na relação. O contrato psicológico estabelece a reciprocidade do empregado baseada no comportamento do empregador, nomeadamente, no grau de cumprimento das suas obrigações para com os empregados. Portanto, o contrato psicológico desenvolve-se na base da reciprocidade do empregado através da incorporação de uma dimensão cognitiva, em que o empregado avalia a diferença entre as obrigações do empregador e o seu cumprimento (Coyle-Shapiro \& Kessler, 2002).

As rupturas e violações do contrato psicológico ocorrem quando existe uma percepção e experiência por parte do empregado de que a organização não cumpriu com uma ou várias obrigações implicadas nesse contrato. Esta percepção desencadeia uma experiência emocional forte, em que o empregado sente ressentimento, injustiça e incómodo. Vários estudos demonstraram que os empregados retribuíam a ruptura do contrato por parte do empregador, isto é, o incumprimento das suas obrigações, através da redução do compromisso organizacional (Coyle-Shapiro \& Kessler, 2002), da redução da confiança no empregador (Robinson \& Rousseau, 1994), da redução do desempenho (Robinson, 1996) e dos comportamentos de cidadania organizacional (Robinson \& Morrison, 1995; Robinson, 1996).

Quando os empregados experimentam mudanças nas práticas de recursos humanos, têm maior probabilidade de perceber uma ruptura ou violação do contrato, favorecendo a percepção desse incumprimento por parte da 
organização, uma avaliação das razões da mudança como menos credíveis e legítimas. As consequências da percepção de ruptura e violação do contrato psicológico têm consequências negativas na confiança e nas relações laborais (Robinson, 1996; Robibson \& Morrison; 1995, 2000; Robinson e Rousseau, 1994), podendo supor-se que numa situação de mudança vão influenciar a sua legitimidade e aceitação. De facto, num contexto de mudança organizacional, Rousseau e Tijoriwala (1999) verificaram que a aceitação e legitimidade das razões da mudança estava associada ao cumprimento das obrigações relacionais por parte da organização.

\section{Esta investigação}

As reformas no sector da saúde tiveram origem na constatação de que existia uma necessidade clara de melhorar a qualidade, o acesso e o nível de serviço na prestação de cuidados de saúde, de acordo com uma filosofia totalmente centrada no cidadão. Por esta razão, o Ministério da Saúde (2004) empreendeu um conjunto de iniciativas das quais se destacam: o Programa Especial de Combate às Listas de Espera Cirúrgicas, o projecto de empresarialização dos hospitais, o lançamento do concurso para novos hospitais em regime de parcerias público-privadas, o aumento do número de vagas nas escolas de medicina, a criação da Entidade Reguladora da Saúde e o lançamento da Rede de Cuidados Continuados.

A transformação de trinta e um hospitais de média dimensão em sociedades anónimas de capitais exclusivamente públicos, tendo como objectivo melhorar a eficiência e o controlo da despesa pública, teve um forte impacto nestas organizações hospitalares, porque obrigou à aplicação de um conjunto de mudanças, que alteraram todo o funcionamento e gestão destas unidades. Concretamente, o sistema de Gestão de Recursos Humanos, sofreu uma mudança integrada nas suas políticas, práticas e técnicas, para ajudar a organização a orientar os esforços para a mudança desejada (Ministério da Saúde, 2004). De facto, verificaram-se as modificações ao nível do planeamento da função dos recursos humanos, ao nível do recrutamento e mobilidade interna, ao nível da avaliação de desempenho, da formação e desenvolvimento, da estrutura salarial e do plano de incentivos.

Nesta investigação, procurou-se compreender como é que os enfermeiros interpretavam as razões destas mudanças e como as aceitavam. Através da teoria do motivo social procurou-se ver quais as razões que os enfermeiros viam para essas mudanças e através da teoria da razão motivada, procurou-se analisar em que medida essas razões eram por si aceites.

Considerámos que as justificações dadas pelos dirigentes das organizações e o modo como planearam e implementaram a mudança, influenciaram as respostas dos enfermeiros. Considerámos que os motivos das razões 
comunicadas por pessoas credíveis (enfermeiros directores) influenciavam a sua aceitação, de tal modo que, quando as razões que eram coumnicadas pelos enfermeiros directores, apoiavam os objectivos das organizações e eram mais aceites.

Por outro lado, considerámos que a implementação de algumas destas umdanças, por implicarem transformação no sistema de recursos humanos, influenciaria positivamente a percepção, por parte dos enfermeiros, da existência de uma ruptura ou violação do contrato psicológico por parte do hospital (Robinson, 1996). Se as rupturas e violações do contrato psicológico ocorrem quando existe uma percepção e experiência por parte do empregado, de que a organização não cumpriu com uma ou várias obrigações implicadas nesse contrato (Morrison \& Robison, 1997), então esta percepção poderá afectar a aceitação das razões das mudanças apresentadas (Rousseau \& Tijoriwala, 1999).

Neste sentido, pretende-se neste estudo analisar em que medida o cumprimento das obrigações do hospital para com os enfermeiros e percepção das razões da mudança influenciam a aceitação das razões de mudança. Por último, pretende-se analisar o efeito dessa aceitação na adopção de comportamentos de cidadania e no desempenho dos enfermeiros prestadores de cuidados. Assim sendo, foram formuladas as seguintes hipóteses:

H 1: As explicações dadas pelas enfermeiras directoras sobre as razões da mudança nas práticas de recursos humanos no hospital influenciaram positivamente a aceitação dessas mudanças; pelo contrario, outras razões não comunicadas não influenciaram a sua aceitação.

H 2: A percepção por parte dos enfermeiros de que o hospital cumpriu com as suas obrigações modera a relação entre as razões da mudança comunicadas e a sua aceitação, de tal modo que as razões da mudança comunicadas são mais aceites quando os enfermeiros consideram que o hospital está a cumprir com as suas obrigações relacionais e balanceadas.

H 3: A aceitação das razões da mudança comunicadas influenciaram a adopção de comportamentos de cidadania organizacional.

H 4: A aceitação das razões da mudança comunicadas influenciaram o desempenho.

\section{Método}

\section{Amostra e Procedimento}

A recolha de dados decorreu entre a segunda quinzena do mês Novembro e o mês de Dezembro de 2004, após as respectivas autorizações dos Conselhos de Administração. Iniciou-se o estudo com uma entrevista a 
enfermeiras directoras e enfermeiros prestadores de cuidados, com o objectivo de se identificarem as principais razões da mudança que ocorreram no sector da saúde, distinguindo entre razões comunicadas e não comunicadas. Prosseguiu-se com a construção das escalas sobre as razões e aceitação da mudança, as quais, juntamente com as de cumprimento do contrato psicológico, foram aplicadas aos enfermeiros prestadores de cuidados. As escalas de desempenho e de comportamentos de cidadania foram preenchidas pelos enfermeiros-chefes ou responsáveis de serviço. Os questionários tinham um código que permitiu fazer a correspondência entre os do enfermeiro e o respectivo chefe, sem pôr em causa o anonimato das respostas. A informação foi recolhida em três hospitais da região de Lisboa, durante o horário de trabalho dos participantes. No início de cada aplicação, explicou-se os objectivos do estudo e, após terminarem o preenchimento, os participantes colocaram os questionários num envelope fechado, o qual entregaram aos invêstigadores. Quando os indivíduos estavam ausentes, os questionários e respectivos envelopes endereçados para devolução dos mesmos foram entregues aos enfermeiros-chefes ou aos responsáveis de serviço.

Este estudo contou com a participação de 467 enfermeiros de três hospitais da região de Lisboa: um centro hospitalar do sector público administrativo (SPA); um hospital central SPA; um hospital sociedade anónima (SA). As equipas de enfermagem são construídas por enfermeiros prestadores de cuidados (com categorias de enfermeiro, enfermeiro graduado e enfermeiro especialista) e enfermeiros com funções de chefia - hierarquia directa (com categoria de enfermeiro-chefe, ou não).

O centro hospitalar SPA apresentava cerca de 600 enfermeiros, o hospital SPA tinha cerca de 550 enfermeiros e o hospital SA era composto por cerca de 500 enfermeiros. Foram distribuídos 570 questionários, 200 no centro hospitalar SPA, 230 no hospital SPA e 140 no hospital SA, a taxa de resposta foi, respectivamente, de $75 \%, 86 \%$ e $86 \%$.

Esta amostra era constituída por $83,9 \%$ de indivíduos do género feminino. A média de idades foi de 31,44 anos (D.P. $=8,4)$, sendo o mínimo 21 e o máximo 68 anos. A maioria dos enfermeiros tinha como habilitações literárias a licenciatura $(61,2 \%)$, apenas $1(0,2 \%)$ tinha mestrado. Relativamente à categoria profissional, $224(48 \%)$ eram enfermeiros, 237 (50,7\%) enfermeiros graduados e $6(1,3 \%)$ enfermeiros especialistas. A grande maioria estava no quadro da função pública $(66 \%)$, no serviço há mais de um ano $(84,9 \%)$ e não acumulava funções noutro hospital $(81,4 \%)$. Os enfermeiros inquiridos trabalhavam em serviços de medicina $(15,8 \%)$, cirurgia $(13,1 \%)$, especialidades médicas $(12,2 \%)$, especialidades cirúrgicas $(22,3 \%)$, unidades de cuidados intensivos $(21,6 \%)$, urgências $(5,6 \%)$ e bloco operatório $(9,4)$. 


\section{Medidas}

Foi realizado um estudo exploratório-descritivo (Fortin, 1999) com objectivo de identificar as principais razões da mudança que ocorreram no sector da saúde e as suas repercussões a nível das práticas de gestão de recursos humanos em enfermagem. A recolha de informação foi efectuada através de entrevistas exploratórias (Quivy \& Campenhoudt, 1992; Rousseau \& Tijoriwala, 1999), a enfermeiros directores e enfermeiros prestadores de cuidados a exercer funções em hospitais do sector público administrativo e hospitais-sociedades anónimas. Foi com base neste estudo que se construíram as medidas das razões da mudança e de aceitação dessas razões.

\section{Razões da mudança}

Foi construída uma escala com 13 itens, com base na análise de conteúdo realizada anteriormente. As medidas das razões e aceitação da umdança, por terem sido construídas neste contexto, foram submetidas a um prócesso de validação através de uma análise factorial confirmatória. Para efectuar a análise confirmatória foi utilizado o programa de equações estruturais de AMOS 5.0 (Arbuckle, 2003) e adoptado o critério de máxima verosimilhança (Maximum Likelihood), A avaliação global da adequação dos modelos (overall goodness-of-fit) foi baseada em vários critérios, tal como $\mathrm{Hu}$ e Bentler (1999) propuseram. Foi realizada a análise de duas estruturas: 1) uma estrutura factorial com 3 factores que foi designada por Modelo $A_{r} ; 2$ ) Uma estrutura factorial com um factor, denominado Modelo $B_{r}$, composto pelos 13 itens que compõem o instrumento de razões da mudança. Verificámos que o Modelo $A_{r}$ reunia todas as condições de aceitação. $O$ indicador SRMR é 0,06 (SRMR $\leq 0,09)$, o TLI é 0,95 (TLI $\geq 0,95)$, o CFI é 0,96 (CFI $\geq$ $0,95)$ e o RMSEA é 0,05 (RMSEA $\leq 0,06)$. O modelo $\mathrm{B}_{\mathrm{r}}$ apresenta todos os indicadores fora dos limites de aceitação. Neste sentido, considera-se que o modelo $\mathrm{A}_{\mathrm{r}}$ é um modelo que tem um bom fit. $\mathrm{O}$ coeficiente de fiabilidade interna para a subescala razão económica é de 0,76 , para a qualidade é de 0,84 e para razões políticas e interesses pessoais é de 0,74 . As duas primeiras subescalas referem-se a razões comunicadas pelas enfermeiras-chefes, enquanto a última subescala refere-se a razões não comunicadas, mas inferidas pelos enfermeiros. Um exemplo de um item de razão económica é "Aumentar a produtividade dos funcionários", de razão de qualidade é "Melhorar a qualidade dos cuidados de saúde" e de razão política é "Razões políticas e ou partidárias". Estes itens foram avaliados, utilizando uma escala que varia de 1 a 5 , ou seja, de "Não foi essa a razão" a "Foi sempre essa a razão". Valores elevados indicam que foi essa a razão da mudança. Os itens 
de 1 a 5 referem-se a razões económicas, de 6 a 9 são razões de qualidade e de 10 a 13 são razões políticas ou interesses pessoais.

\section{Aceitação das razões}

A escala para medir a aceitação das razões foi construída com base nos 13 itens utilizados para medir as razões da mudança. Foi realizada a análise factorial de duas estruturas: 1) uma estrutura factorial com 3 factores, que foi designada por Modelo A; 2) Uma estrutura factorial com um factor, denominado Modelo B, composto pelos 13 itens que compõem o instrumento de aceitação das razões da mudança. Verificámos que o Modelo A reunia as condições de aceitação nos indicadores SRMR $=0,07$ (SRMR $\leq 0,09)$, no TLI é 0,96 (TLI $\geq 0,95)$ e no CFI é 0,97 (CFI $\geq 0,95)$. Relativamente ao RMSEA, este é de 0,065 (RMSEA $\leq 0,06$ ), logo não cumpre os critérios de aceitação. $\mathrm{O}$ modelo $\mathrm{B}$ apresentava todos os indicadores fora dos limites de aceitação. No entanto, considera-se que o modelo A é um modelo que tem um fit aceitável. O coeficiente de fiabilidade interna para a subescala Aceitação das Razões Económicas é de 0,88, para a Aceitação das Razões de Qualidade é de 0,94 e para a Aceitação das Razões Políticas é de 0,88 . Um exemplo de um item de aceitação da razão económica é "Controlar a despesa e eliminar os desperdícios", de aceitação da razão de qualidade é "Aumentar a satisfação dos utentes e a acessibilidade aos cuidados de saúde" e de aceitação da razão política é "Adesão a políticas e práticas de gestão que estão na moda". Estes itens foram avaliados, utilizando uma escala que varia de 1 a 5, ou seja, "Não foi aceitável" a "Foi sempre aceitável". Valores elevados indicam que a razão da mudança foi considerada aceite. Os itens de 1 a 5 referem-se a aceitação de razões económicas, de 6 a 9 a aceitação de razões de qualidade e de 10 a 13 de aceitação de razões políticas ou interesses pessoais.

\section{Obrigações da organização}

As obrigações da organização foram medidas, utilizando uma adaptação da escala de Hui, Lee e Rousseau (2004), seleccionando dois tipos de obrigações, por serem as escolhidas para as hipóteses deste estudo. O instrumento utilizado por Hui, Lee e Rousseau (2004) contém 15 itens para as obrigações balanceadas e 10 para as relacionais. Foi pedido aos enfermeiros que reflectissem sobre as obrigações do hospital para com eles e que indicassem quanto consideravam que o hospital estava obrigado a dar-lhes os diferentes benefícios indicados. Estes itens eram avaliados numa escala que variava de 1 a 5, desde "Não tem esta obrigação" a "Tem muitíssimo esta obrigação". Um exemplo de item de obrigação "balanceada" é "Dar-me objectivos de desempenho mais desafiantes" e de obrigação relacional é 
"Proporcionar-me um emprego estável". Valores elevados indicam que a organização tem essa obrigação.

Por não haver uma tradução para a língua portuguesa deste instrumento procedeu-se inicialmente a uma processo de retroversão do instrumento. A escala inicial foi fornecida na língua inglesa e procedeu-se à sua tradução para a língua portuguesa. Posteriormente, pediu-se a um tradutor que procedesse à tradução desta versão portuguesa novamente para a língua inglesa. Foi efectuado um pré-teste da medida, através da aplicação do questionário a 6 enfermeiros de um hospital SPA e a 4 de um hospital SA, onde foi possível certificar quer a compreensão dos itens, quer a sua aplicabilidade ao contexto do estudo. Da escala de obrigações de Hui, Lee e Rousseau (2004) foram retirados dois itens, uma vez que não faziam sentido no contexto em estudo e outros dois foram colocados de forma positiva, de acordo com sugestões do pré-teste.

Foi realizada uma análise factorial exploratória a este instrumento e a extracção dos factores foi realizada com base no método de análise em componentes principais com rotação varimax e delimitação de 2 factores. $\mathrm{Na}$ selecção dos itens relativos a cada factor, foram utilizados três critérios: depois de ter sido realizada a rotação varimax, foram seleccionados os itens saturados a mais de 0,50 , foram eliminados os itens que apresentavam pesos factoriais superiores a 0,25 em vários factores simultaneamente (itens ambíguos) e foram calculados os alfas de Cronbach, a correlação entre itens e valor global da escala, bem como do valor do $\alpha$ caso o item fosse eliminado. O factor I explica $25,8 \%$ da variância total, inclui os itens O1, O3, $\mathrm{O} 4, \mathrm{O} 9, \mathrm{O} 12$ e O14, ou seja, itens correspondentes à subescala das obrigações balanceadas, e apresenta um $\alpha$ de Cronbach de 0,76. O factor II explica $9,9 \%$ da variância total, inclui os itens O15, O19, O20, O23 e O24, isto é, itens que correspondem à subescala das obrigações relacionais, e apresenta um $\alpha$ de Cronbach de 0,88 .

\section{Benefícios}

Os benefícios obtidos pelos enfermeiros foram medidos, utilizando itens semelhantes ao da escala anterior, mas avaliados numa escala de 5 pontos, correspondendo 1 a "Não me tem dado" e 5 a "Tem-me dado muitíssimo". Valores elevados indicam que a organização tem dado esses benefícios aos enfermeiros.

A subescala relativa aos benefícios balanceados apresenta um $\alpha$ de Cronbach de 0,89 e a escala relativa aos benefícios relacionais apresenta um $\alpha$ de Cronbach de 0,81 . 


\section{Cumprimento das obrigações}

Para medir o cumprimento do contrato seguiram-se as recomendações de Robinson (1996) relativamente à ruptura do contrato psicológico. A medida de cumprimento do contrato psicológico foi calculada através da diferença entre as percepções dos enfermeiros relativamente aos benefícios obtidos e as obrigações do hospital. Os scores agregados variam de -4 a +4 , assim, um score de +4 indica que as obrigações se apresentam bastante cumpridas e um score -4 indica que não foram cumpridas as obrigações.

\section{Desempenho}

O desempenho foi medido, utilizando uma adaptação da escala de Williams e Anderson (1991). Esta medida continha 6 itens com respostas numa escala que variava de 1 a 5, desde 'Quase nunca' a 'Quase sempre'. Um exemplo de item é 'Cumpre as tarefas que lhe foram destinadas'. Estes comportamentos foram avaliados pelo supervisor ou coordenador directo do trabalhador e elevados valores indicam elevado desempenho. O coeficiente de fiabilidade interna, $\alpha$ de Cronbach, é de 0,93.

\section{Comportamentos de Cidadania Organizacional}

Foram seguidas as recomendações de Van Dyne, Graham e Dienesch (1994) relativamente a um tipo específico de comportamento de cidadania, relevante para o objecto de estudo. Como a aceitação da mudança consiste numa atitude face à organização, considerou-se que as suas influências se relacionariam mais com comportamentos relacionados com a organização, do que com comportamentos relacionados com supervisores ou colegas. Das cinco dimensões de comportamentos de cidadania identificados por Organ (1988), foram escolhidos os comportamentos de virtude civica (comportamentos que indicam que o trabalhador participa de forma responsável e está envolvido com a vida da organização) por se considerar que era a dimensão mais directamente relacionada com a organização (Robinson \& Morrison, 1995). Foram utilizados os itens desta dimensão usados por Morrison (1994). A medida contém 6 itens com respostas que variam de 1 a 5, de 'Quase nunca' a 'Quase sempre'. Um exemplo de item é 'Pensa no que é melhor para esta empresa'. Estes comportamentos de virtude cívica foram avaliados pelo supervisor ou coordenador directo do trabalhador e resultados elevados indicam uma elevada presença destes comportamentos. O coeficiente de fiabilidade interna, $\alpha$ de Cronbach é de 0,92 . 


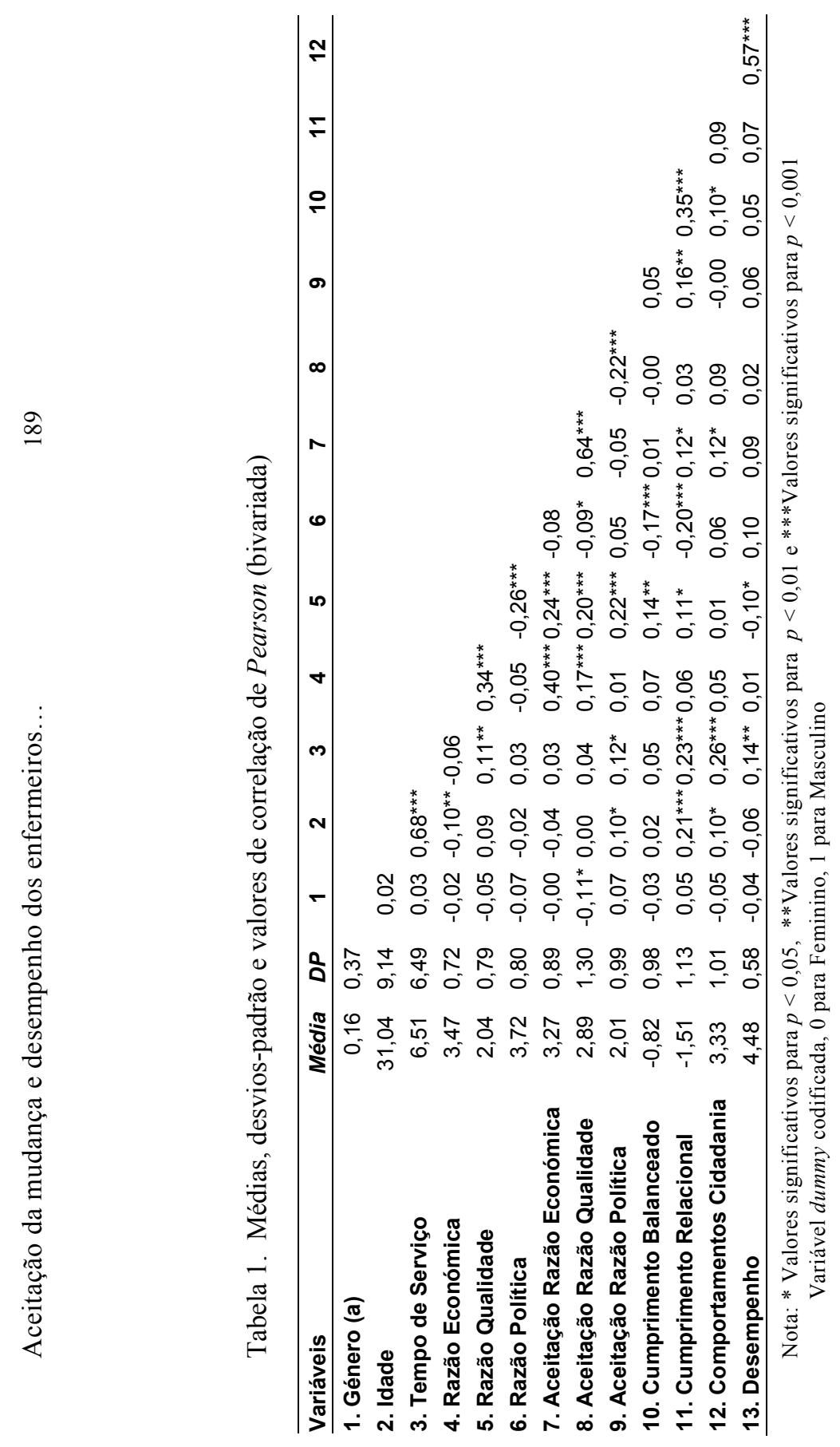




\section{Variáveis-Controlo}

A idade, o género (Coyle-Shapiro \& Kessler, 2002), a experiência profissional (Coyle-Shapiro \& Kessler, 2002; Robinson, 1996) são variáveis com influência na percepção do cumprimento das obrigações e nas contribuições dos empregados, por isso considerámos importante controlar o seu efeito. Deste modo, controlou-se o género, codificado como variável dummy (Cohen, Cohen, West \& Aiken, 2003) em que "0" é Feminino e "1" Masculino; a idade e a experiência profissional (em anos).

\section{Resultados}

Na tabela que se segue são apresentados os seguintes indicadores estatísticos: as médias, os desvios-padrão e os valores de correlação de Pearson das variáveis estudadas.

Os enfermeiros inquiridos consideram que as mudanças implementadas tiveram essencialmente razões políticas e interesses pessoais. As razões económicas comunicadas pela direcção também foram consideradas motivos da mudança, enquanto as razões de qualidade, também comunicadas pela direcção, não foram consideradas razões de mudança. Como era de esperar, as razões políticas não foram aceites pelos enfermeiros, enquanto as razões económicas tiveram alguma aceitação. Durante o processo, os enfermeiros consideraram que o hospital teve algum incumprimento das suas obrigações, quer balanceadas quer relacionais, sendo mais elevado para as segundas. As chefias directas consideram que estes enfermeiros manifestam alguns comportamentos de cidadania organizacional e níveis de desempenho bastante elevados.

Como esperado, as razões económicas relacionaram-se positivamente com a aceitação dessas razões $(r=0,40, p<0,001)$, as razões de qualidade com a aceitação dessas razões $(r=0,20, p<0,001)$ e as razões políticas não apresentam relação com a aceitação dessas razões $(r=0,05$, n.s. $)$. A percepção dos enfermeiros de que o hospital está a cumprir as obrigações relacionais associa-se positivamente à aceitação das razões económicas $(r=0,12$, $p<0,05)$. Os comportamentos de cidadania organizacional estão associados positivamente à aceitação das razões económicas $(r=0,12, p<0,05)$.

Para testar a hipótese H 1 que supõe que as razões económicas e de qualidade da mudança estarão positivamente relacionadas com a aceitação destas razões, não se observando influência das razões não comunicadas (políticas e pessoais) na sua respectiva aceitação, procedeu-se a análises de regressão hierárquica. 


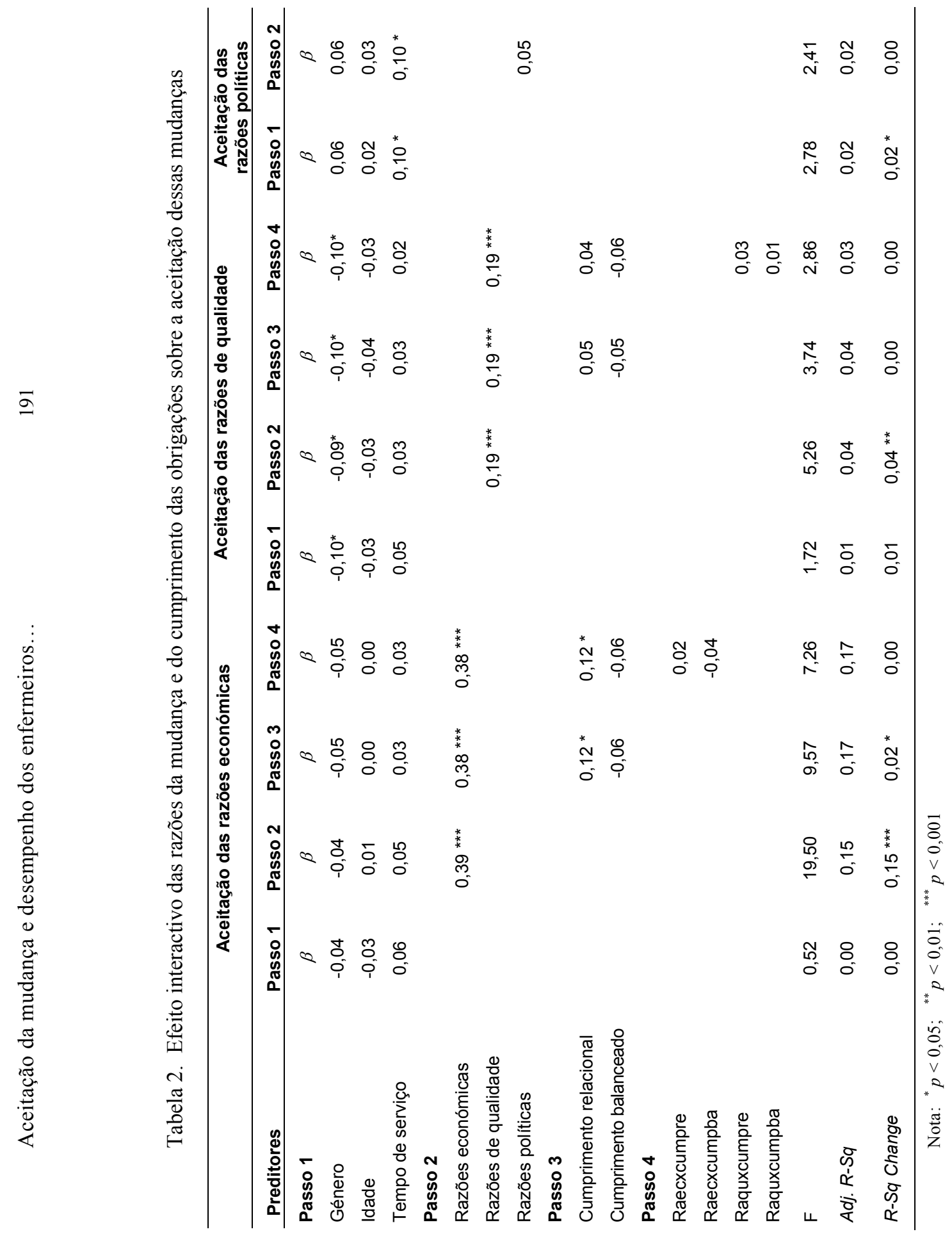


Depois de introduzidas as variáveis-controlo e como esperado, verificámos que as razões económicas contribuem para explicar a aceitação dessas razões $(\beta=0,39, \rho<0,001)$, as razões de qualidade contribuem para a aceitação dessas razões $(\beta=0,19, \rho<0,001)$, mas as razões políticas não contribuem significativamente para a sua aceitação $(\beta=0,05$, n.s. $)$. A hipótese $\mathrm{H} 1$ foi suportada pelos dados.

Para testar a H 2 que pressupõe que a percepção por parte dos enfermeiros de que o hospital está a cumprir com as suas obrigações modera a relação entre as razões da mudança comunicadas e a sua aceitação, utilizou-se o modelo de moderação (Baron \& Kenny, 1986). Os resultados foram analisados recorrendo a análises de regressão hierárquica, de forma a testar os efeitos principais e de interacção das variáveis sobre a aceitação das razões económicas e aceitação das razões de qualidade. Neste sentido, num primeiro passo, foram introduzidas as variáveis controlo, num segundo passo, as independentes e no passo seguinte as variáveis de interacção (obtidas através da criação de novas variáveis que são o produto da variável moderadora e das razões da mudança). Antes de realizar esta análise, seguindo as indicações de Cohen, Cohen, West e Aiken (2003), foram centradas as variáveis independente e moderadora (subtraindo à própria variável a sua média: $\mathrm{A}-\mathrm{M}_{\mathrm{A}}$ ), de modo a lidar com as questões de multicolineariedade que derivam dos termos de interacção.

Como se pode observar na tabela 2, ao contrário do previsto, o cumprimento das obrigações relacionais ou balanceadas não tem um efeito de interacção com as razões económicas e de qualidade. A hipótese 2 não foi suportada pelos dados.

No entanto, verificamos que o cumprimento das obrigações relacionais tem um efeito positivo sobre a aceitação das razões económicas $(\beta=0,12, \rho<0,05)$, mostrando que este cumprimento pode promover a aceitação destas razões.

Por último, para testar as Hipótese $\mathrm{H} 3$ e H 4 que supõem que a aceitação das razões económicas e de qualidade da mudança influenciam positivamente os comportamentos de cidadania organizacional e o desempenho, realizaram-se análises de regressão linear em que se regrediu cada indicador dos comportamentos de virtude cívica e do desempenho da tarefa sobre a aceitação das razões económicas e sobre a aceitação das razões de qualidade.

Pela observação da tabela 3, podemos observar que, depois de introduzidas as variáveis-controlo e como esperado, a aceitação das razões económicas influencia positivamente os comportamentos de virtude cívica dos enfermeiros $(\beta=0,11, \rho<0,05)$. No entanto, ao contrário do esperado, a aceitação das razões de qualidade não influenciaram estes comportamentos $(\beta=0,07, n . s$.$) . A hipótese 3$ foi, assim, suportada parcialmente pelos nossos dados. 
Pela observação da tabela 3, podemos observar que, depois de introduzidas as variáveis-controlo e ao contrário do esperado, a aceitação das razões económicas não influencia significativamente o desempenho dos enfermeiros $(\beta=0,07, n . s$. $)$, nem a aceitação das razões de qualidade influenciaram o desempenho $(\beta=0,00, n . s$. $)$. A hipótese 4 não foi suportada pelos nossos dados.

Tabela 3. Efeito da aceitação das mudanças comunicadas nos comportamentos de virtude cívica e no desempenho dos enfermeiros

\begin{tabular}{|c|c|c|c|c|c|c|c|c|}
\hline \multirow[t]{2}{*}{ Preditores } & \multicolumn{5}{|c|}{ Comportamentos de cidadania } & \multicolumn{3}{|c|}{ Desempenho } \\
\hline & $\beta$ & $\beta$ & $\beta$ & $\beta$ & $\beta$ & $\beta$ & $\beta$ & $\beta$ \\
\hline \multicolumn{9}{|l|}{ Passo 1} \\
\hline Idade & $-0,12^{*}$ & $-0,12^{*}$ & $-0,09$ & $-0,09$ & $-0,26^{\star * *}$ & $-0,25^{\star * *}$ & $-0,24^{\star * *}$ & $-0,24^{\star * *}$ \\
\hline Género & $-0,06$ & $-0,06$ & $-0,06$ & $-0,05$ & $-0,04$ & $-0,04$ & $-0,04$ & $-0,04$ \\
\hline Tempo Serviço & $0,35^{\star * *}$ & $0,34^{\star * *}$ & $0,33^{* * *}$ & $0,32^{\star * *}$ & $0,33^{* * *}$ & $0,33^{* * *}$ & $0,32^{* * *}$ & $0,32^{\star * *}$ \\
\hline \multicolumn{9}{|l|}{ Passo 2} \\
\hline $\begin{array}{l}\text { Aceitação Razões } \\
\text { Económica }\end{array}$ & & $0,11^{*}$ & & & & 0,07 & & \\
\hline $\begin{array}{l}\text { Aceitação Razões } \\
\text { Qualidade }\end{array}$ & & & & 0,07 & & & & 0,00 \\
\hline$F$ & 13,25 & 11,40 & & & 9,04 & 7,44 & 8,95 & 6,70 \\
\hline Adj. R-Sq & 0,08 & 0,10 & 0,08 & 0,08 & 0,05 & 0,05 & 0,06 & 0,06 \\
\hline$R$-Sq Change & $0,08^{* * *}$ & $0,02^{*}$ & $0,08^{* * *}$ & 0,01 & $0,06^{* * *}$ & 0,00 & $0,06^{* * *}$ & 0,00 \\
\hline
\end{tabular}

Nota: $* p<0,05 ; * * p<0,01 ; * * * p<0,001$

\section{Discussão}

Os objectivos deste estudo consistiram em identificar quais os factores que influenciam a aceitação das mudanças hospitalares, nomeadamente a influência do cumprimento das obrigações do hospital e das razões dessa mudança, assim como analisar o efeito dessa aceitação nos comportamentos de cidadania e no desempenho dos enfermeiros.

Foram utilizados alguns pressupostos da teoria do motivo social, da teoria da razão motivada e da teoria do contrato psicológico, para explicar o processo de aceitação desta mudança por parte dos enfermeiros. 
Os resultados obtidos permitem confirmar que as razões da mudança quando são comunicadas pelos agentes organizacionais e estando enquadradas nos objectivos organizacionais (motivos económicos e de qualidade), vão influenciar a sua aceitação por parte dos empregados. Estes resultados são consistentes com a teoria do motivo social, uma vez que permitem compreender a importância dos enfermeiros directores comunicarem os motivos das razões da mudança nas práticas de gestão de recursos humanos em enfermagem, para que estas sejam aceites pelos enfermeiros prestadores de cuidados. No estudo de Rousseau e Tijoriwala (1999), apenas as razões de qualidade para a mudança foram consideradas legítimas, enquanto que, neste estudo, as razões económicas foram as mais aceites.

Por outro lado, também se verificou que, provavelmente, a eficácia da comunicação das razões da mudança foi baixa (Rousseau, 1996), levando a que se desenvolvessem significações e interpretações activas por parte dos enfermeiros (Weick, 1995, cit. por Rousseau \& Tijoriwala, 1999). De facto, não só os enfermeiros não consideraram as razões de qualidade comunicadas pelas chefias como razões da mudança, como também consideraram que razões políticas não comunicadas eram os principais motivos destas mudanças. Como referiu uma enfermeira de um hospital SPA - "Na SPA, acho que é uma desorganização completa. Não são traçados objectivos, ou se eles existem não passam para os trabalhadores, para a parte operacional. Não existe informação". "As pessoas sentem-se inseguras. Há uma insegurança muito grande. A nível monetário e a nível profissional. E um sentimento de descontentamento". Deste modo, os resultados obtidos neste estudo também suportam o argumento de que, quando a comunicação não é suficiente, os colaboradores encontram outras razões explicativas para a mudança, as quais podem não ser legítimas e aceitáveis (Rousseau, 1996; Rousseau \& Tijoriwala, 1999).

Nesta investigação também foi possível verificar que o cumprimento das obrigações relacionais tem um papel importante na aceitabilidade das razões da mudança económicas. Estes resultados enquadram-se na teoria da razão motivada (Ajzen, 1985; McGill, 1989, cit. por Rousseau \& Tijoriwala, 1999), em que a aceitação das explicações dadas pelos responsáveis hierárquicos (enfermeiros directores) está relacionada com a confiança que os enfermeiros prestadores de cuidados têm nos seus superiores, sendo esta confiança a base para o estabelecimento do contrato psicológico entre organização e colaborador (Robinson \& Morrison, 1995; Robinson, 1996). O contrato psicológico caracteriza, deste modo, a relação do enfermeiro com a organização e reforça a crença nas razões apresentadas para implementar a mudança (Rousseau \& Tijoriwala, 1999). Daí que os resultados deste estudo confirmem que o cumprimento das obrigações relacionais contribua para a aceitação das razões económicas. Assim, podemos supor que, 
quando o hospital cumpre as obrigações relacionais, como, por exemplo, garantir estabilidade e segurança de emprego e promover o apoio pessoal e o bem-estar, os níveis de confiança nos gestores aumentam (Rousseau \& Tijoriwala, 1999) e, consequentemente, a aceitação das razões da mudança que por si foram comunicadas. Numa próxima investigação, a confiança será uma variável a incluir no estudo da aceitação da mudança.

Ao contrário do que era esperado, não se verificou os efeitos do cumprimento das obrigações dos hospitais sobre a aceitação das razões de qualidade. A explicação provável poderá ser o facto de as razões de qualidade não serem consideradas como o motivo da mudança, não sendo, por isso, a sua aceitação influenciada pelo cumprimento das obrigações.

De acordo com o esperado, verificou-se que a aceitação das razões económicas era um bom preditor dos comportamentos de virtude cívica. Quando os enfermeiros aceitam os motivos económicos para implementação das mudanças nas organizações, mais facilmente se empenham na consecução dos objectivos organizacionais e, consequentemente, adoptam comportamentos de virtude cívica. Podemos considerar que, devido à emergência de uma relação de reciprocidade, quando os enfermeiros aceitam os motivos económicos das mudanças, sentem-se obrigados a executar tarefas extraformais e extracontratuais. Os enfermeiros, quando são submetidos a mudanças e essas mudanças são consideradas legítimas, respondem de forma recíproca (Gouldner, 1960), desempenhando comportamentos extra-papel ou contextuais.

Os resultados deste estudo permitem, assim, verificar que o cumprimento das obrigações relacionais relaciona-se positivamente com a aceitação das razões económicas apresentadas pelos superiores e essa aceitação, por sua vez, relaciona-se positivamente com a adopção de comportamentos de virtude cívica. Em estudos anteriores, verificou-se que o cumprimento das obrigações das organizações podia estar relacionado indirectamente com os comportamentos de virtude cívica. Especificamente, Hui, Lee e Rousseau (2004) mostraram que o cumprimento do contrato psicológico relacional associado à instrumentalidade (a crença de que certos comportamentos levam a um resultado) é que permite a adopção de comportamentos de virtude cívica. Nesta investigação, como pressuposto, foi possível verificar que, em situações de mudança, se os responsáveis organizacionais não querem diminuir os níveis de comportamentos de virtude cívica dos colaboradores devem promover a aceitação da mudança, a qual ocorre quando se cumpre as obrigações estabelecidas no contrato, em particular, as relacionais. Além disso, os responsáveis organizacionais devem comunicar as razões dessa mudança, de modo a integrá-la em valores e pressupostos partilhados e, consequentemente, obterem a adesão destes aos objectivos dessa mudança. 
Neste estudo, e ao contrário do previsto, a aceitação das razões económicas e de qualidade da mudança não influencia o desempenho das tarefas dos enfermeiros. Embora estes colaboradores hospitalares possam ou não aceitar os motivos da mudança, o seu nível de desempenho não é afectado por essa aceitação. Provavelmente, porque os enfermeiros centram a sua atenção nas pessoas doentes, agindo num limiar da vida e da morte, visando o restabelecimento da saúde das pessoas, o seu desempenho não é posto em causa em nenhum momento. Além disso, a responsabilidade inerente ao papel do enfermeiro é regulamentada pelo código deontológico, o qual garante a qualidade dos cuidados de enfermagem ao cidadão. Deste modo, os enfermeiros têm a responsabilidade de proteger aqueles a quem prestam cuidados, tendo por base um conjunto de valores universais da profissão. Por outro lado, um deficiente desempenho do conteúdo funcional e insuficiente ou deficiente relacionamento com o utente, família, grupos ou comunidade e pessoal do respectivo local de trabalho, pode levar à atribuição de uma avaliação de desempenho negativa (Art. $49 .^{\circ}$ do Decreto-Lei n. ${ }^{\circ}$ 437/91, de 8 de Novembro ${ }^{4}$ ), a qual implica a não progressão horizontal e vertical e uma penalização a nível monetário.

\section{Conclusão}

Os resultados obtidos contribuem para aumentar o nosso conhecimento sobre a aceitação da mudança organizacional por parte dos empregados, especificamente quando implica modificações nas práticas de recursos humanos. Em primeiro lugar, os resultados do estudo são congruentes com outros estudos, ao indicarem que quando as razões da mudança são comunicadas pelos responsáveis, serão mais facilmente aceites e consideradas legítimas (Rousseau \& Tijoriwala, 1999). Nesse sentido, é importante que os agentes organizacionais transmitam intenções positivas de forma credível e proporcionem informação objectiva sobre os motivos das suas decisões (Rousseau, 1995).

Em segundo lugar, obteve-se apoio para a ideia de que o cumprimento das obrigações relacionais influencia a aceitação das mudanças, motivadas por razões económicas. Estes resultados estão em sintonia com as conclusões de Cotton (1993, cit, Chambel \& Peiró, 2003), que destaca a necessidade de ter em conta não só o conteúdo da mudança, mas também o processo das mudanças para compreender as repercussões nas práticas de recursos humanos. Assim, além dos motivos que levaram à implementação das mudanças, interessa compreender como ocorreu este processo e, concretamente, em que medida este processo pôs ou não em causa o cumprimento das obrigações do hospital para com os enfermeiros. 
Por último, ao analisar este fenómeno do ponto de vista organizacional, verificou-se que quando as mudanças nessas práticas de recursos humanos eram aceites, os enfermeiros respondiam reciprocamente para com a organização, exibindo comportamentos de cidadania organizacional, nomeadamente comportamentos de virtude cívica. Ao adoptarem este tipo de comportamentos, "vestem a camisola da organização", aderindo mais facilmente aos objectivos organizacionais.

Em termos práticos, se o hospital cumpre as suas obrigações relacionais e os responsáveis facilitam a aceitação das mudanças, através da comunicação de razões credíveis, especificamente as que têm motivos económicos, os enfermeiros ajustam mais facilmente os objectivos individuais aos organizacionais (Alchian \& Demsetz, 1972; Williamson, 1975, cit. por Robinson, 1996), adoptando comportamentos de virtude cívica.

\section{Méritos e Limitações}

Podemos salientar como mérito desta investigação o facto de ter sido realizada em contexto prático e tem repercussões na implementação de mudanças nos hospitais e no modo como os envolvidos aceitam e reagem às mudanças.

Do ponto de vista metodológico, o presente estudo apresentou vários aspectos positivos que são de realçar: para analisar as razões e aceitação das razões das mudanças, foram construídas medidas adaptadas ao contexto destes hospitais, através do recurso a metodologias qualitativas; foram adaptadas medidas internacionais ao contexto português, nomeadamente, as medidas de Contrato Psicológico (Hui, Lee \& Rousseau, 2004), de Desempenho (Williams \& Anderson, 1991) e de Comportamentos de Virtude Cívica (Van Dyne, Graham \& Dienesch, 1994); realizaram-se validações das medidas, com recurso a análise factorial confirmatória ou exploratória; seguiram-se as recomendações de Robinson e Morrison $(1995,2000)$ para evitar o erro da variância comum e foram utilizadas medidas de hetero-avaliação, para medir o desempenho e os comportamentos de virtude cívica, através das avaliações realizadas por parte dos enfermeiros-chefes ou enfermeiros responsáveis do serviço (funções de chefia).

No entanto, esta investigação tem algumas limitações que devem ser reconhecidas. Em primeiro lugar, estes resultados referem-se ao contexto hospitalar, não podendo ser generalizados sem ser replicada noutros sectores de actividade. Em segundo lugar, este estudo foi realizado num só momento (transversal), não permitindo, por isso, verificar relações causais entre as variáveis. Por exemplo, embora do ponto de vista teórico se tenha pressuposto a influência do cumprimento das obrigações na aceitação da mudança e desta nos CCO dos enfermeiros, é igualmente plausível supor 
que são enfermeiros que exibem menos $\mathrm{CCO}$ que aceitam menos a mudança e consideram que o hospital menos cumpriu com as suas obrigações, nesta situação. Numa próxima investigação longitudinal, seria importante avaliar a percepção das obrigações da organização num tempo $\left(\mathrm{t}_{1}\right)$ e a percepção do cumprimento das obrigações, assim como as respostas comportamentais dos colaboradores num tempo $\left(\mathrm{t}_{2}\right)$.

A terceira limitação possível desta investigação está associada à medida do grau de cumprimento das obrigações por parte da organização, ou seja, foi feita a agregação dos itens que foram percebidos como cumprimento e como ruptura, deste modo, as ponderações para a percepção do cumprimento e de ruptura são equivalentes. Além disso, as pessoas podem ter mais sensibilidade para perceberem as rupturas em detrimento do cumprimento das obrigações. Outra limitação relacionada com esta medida é que umas pessoas podem valorizar mais uns itens que outros e, por isso, atribuem diferentes pesos perante a mesma situação.

\section{Referências}

Arbuckle, J. L.(2003). AMOS 5.0 user's guide. Chicago: SmallWaters Corporation.

Bies, R. J. (1987). The predicament of injustice: the management of moral outrage. In L.L.Cummings \& B. M. Staw (Eds.), Research in organizational behavior (vol. 9, pp. 289-319). Greenwich, CT: JAI Press.

Bies, R. J. \& Moag, J. S. (1986). Interactional justice: communication criteria of fairness. In M. H. Barzerman, R. Lewicki \& B. Sheppard (Eds.), Research on negotiations in organizations (vol. 1, pp. 43-55). Greenwich, CT: JAI Press.

Bies, R. J. \& Shapiro, D. L. (1993). Interactional fairness judgements: the influence of causal accounts. Social Justice Research, 1, 199-218.

Blau, P. M. (1964). Exchange and power in social life. New York: Wiley.

Chambel, M. J. \& Peiró, J. M. (2003). Alteraciones en las prácticas de gestión de recursos humanos y violación del contrato psicológico. Arxius, 8, 105-131.

Cohen, J., Cohen, P., West, S. G. \& Aiken, L. S. (2003). Applied multiple regression/correlation analysis for the behavioral sciences ( $3^{\text {rd }}$ Edition). Mahwah, NJ: Lawrence Erlbaum Associates Publishers.

Coyle-Shapiro, J. \& Kessler, I. (2002). Imploring reciprocity through the lens of the psychological contract: employee and employer perspectives. European Journal of Work and Organizational Psychology, 11, 69-86.

Einhorn, H. J. \& Hogarth, R. M. (1986). Judging probable cause. Psychological Bulletin, 99, 3-19.

Fairhurst, G. T. \& Sarr, R. A. (1996). The art of framing: managing the language of leadership. San Francisco: Jossey-Bass.

Fortin, M. F. (1999). O processo de investigação: da realização à prática. Loures: Lusociência. 
Gouldner, A. (1960). The norm of reciprocity: a preliminary statement. American Sociological Review, 25, 161-179.

Hu, L. \& Bentler, P. M. (1999). Cut-offs criteria for fit indexes in covariance structure analysis: conventional criteria versus new alternatives. Strutural Equation Modeling, 6, 1-55.

Hui, C., Lee, C. \& Rousseau, D. M. (2004). Psychological contracts and organizational citizenship behavior in China: investigating generalizability and instrumentalty. Journal of Applied Psychology, 89, 311-321.

Huy, Q. N. (1999). Emotional capability, emotional intelligent, and radical change. Academy of Management Review, 24, 325-345.

McGill, A. L. (1995). American and they manager' explanations for poor company performance: role of perspective and culture in cause selection. Organizational Behavior and Human Decision Processes, 61, 16-27.

Ministério da Saúde (2004). Projectos da Unidade de Missão dos Hospitais SA. www.hospitaissa.min-saude.pt/Hospitais_SA/Projectos_UM/projectos_transversais/ Comunicare/PROJECTOS UNIDADE MISSĀO.htm, Retirā̄o em 14 de Maio de 2005.

Morrison, E. W. (1994). Role definitions and organizational citizenship behavior: the importance of employee's perspective. Academy of Management Journal, 37, 1543-1567.

Organ, D. W. (1988). Organizational citizenship behavior: the good soldier syndrome. Lexington: Lexington Books.

Pfeffer, J. (1994). Competitive advantage through people: unleashing the power of the workforce. Boston: Harvard Business School Press.

Quivy, R. \& Campenhoudt, L. V. (1992). Manual de investigação em ciências sociais. Lisboa: Gradiva.

Robinson, S. L. (1996). Trust and breach of psychological contract. Administrative Science Quarterly, 41, 574-599.

Robinson, S. L. \& Morrison, E.W. (1995). Psychological contracts and OCB: the effect of unfulfilled obligations on civic virtue behavior. Journal of Organizational Behavior, 16, 289-298.

Robinson, S. L. \& Morrison, E. W. (1997). When employees feel betrayed: a model of how psychological contract violation develops. Academy of Management Review, 16, 92-120.

Robinson, S. L. \& Morrison, E. W. (2000). The development of psychological contract breach and violation: a longitudinal study. Journal of Organizational Behavior, 21, 525-546.

Robinson, S. L. \& Rousseau, D. M. (1994). Violating the psychological contract: not the exception but the norm. Journal of Organizational Behavior, 15, 245-298.

Rousseau, D. M. (1989). Psychological and implied contract in organizations. Employee Rights and Responsibilities Journal, 2, 121-139.

Rousseau, D. M. (1995). Psychological contract in organizations: understanding written and unwritten agreements. Thousand Oaks, CA: Sage

Rousseau, D. M. (1996). Changing the deal while keeping the people. Academy of Management Executive, 10, 50-61. 
Rousseau, D. M. (2000). Psychological contract inventory: technical report (Tech. Rep. N. ${ }^{\circ}$ 2). Pittsburgh, PA: Carnegie Mellon University.

Rousseau, D. M. \& Tijoriwala, S. A. (1999). What's a good reason to change? Motivated reasoning and social accounts in promoting organizational change. Journal of Applied Psychology, 84, 514-528.

Simon, H. A. \& March, J. G. (1958). Teoria de la organización. Barcelona: Ariel.

Sitkin, S. B. \& Bies, R. J. (1993). Social accounts in conflict situations: using explanations to manage conflict. Human Relations, 46, 349-370.

Shapiro, D. L., Buttner, E. H. \& Barry, B. (1994). Explanations: what factors enhance their perceived adequacy? Organizational and Human Decision Processes, 58, 346-36.

Van Dyne, L., Graham, J. W. \& Dienesch, R. M. (1994). Organizational citizenship behavior: construct redefinition, measurement and validation. Academy of $M a-$ nagement Journal, 37, 765-802.

Williams, L. J. \& Anderson, S. E. (1991). Job satisfaction and organizational commitment as predictors of organizational citizenship and in-role behaviors. Journal of Management, 17, 601-617. 